\title{
Effect of the application of different concentrations of EDTA on the adhesion of fiber posts using self-adhesive cements
}

Yançanã Luizy GRUBER(a)

Renata Terumi JITUMORI(a)

Thaís Emanuelle BAKAUS(a) iD

Alessandra REIS(a)

João Carlos GOMES(a) iD

Giovana Mongruel GOMES(a)

(a) Universidade Estadual de Ponta Grossa - UEPG, School of Dentistry, Department of Restorative Dentistry, Ponta Grossa, PR, Brazil.
Declaration of Interests: The authors certify that they have no commercial or associative interest that represents a conflict of interest in connection with the manuscript.

\section{Corresponding Author:}

Giovana Mongruel Gomes

E-mail: giomongruel@gmail.com

https://doi.org/10.1590/1807-3107bor-2021.vol35.0012

Submitted: Mar 22, 2020

Accepted for publication: July 27, 2020

Last revision: August 26, 2020
Abstract: The purpose of this study was to analyze the effect of the application of different concentrations of EDTA on the adhesion of fiber posts to root dentin using self-adhesive resin cements. After endodontic treatment, 78 single roots were randomly divided into six groups $(n=13)$ according to the combination of the following factors: surface dentin treatment - control (distilled water), 17\% EDTA and 24\% EDTA; and self-adhesive resin cement - RelyX U200 (RX); and Multilink Speed (ML). After fiber post cementation, six slices were obtained for each root. Ten roots of each group were used for bond strength (BS) and three for microhardness $(\mathrm{MH})$ evaluations. Data obtained from BS and $\mathrm{MH}$ tests for each resin cement were subjected to two-way ANOVA (surface treatment vs. root region) and to a post-hoc Tukey's test ( $\alpha=0.05)$. The lowest BS value was observed in the $24 \%$ EDTA group for RX cement, whereas the highest values for ML cement were observed for the control group in the middle and apical regions. In the MH test, the lowest value for RX was observed for 24\% EDTA in the cervical region, whereas and the highest value for the ML cement was observed in the control group. Regarding both self-adhesive resin cements tested, the application of $24 \%$ EDTA was not able to improve the adhesion of fiber posts to root canal.

Keywords: Edetic Acid; Resin Cements; Dentin.

\section{Introduction}

Fiber posts are commonly used in the reconstruction of teeth with extensive coronal destruction, since endodontically-treated teeth are more prone to fractures than are vital teeth. ${ }^{1}$ Post systems minimize masticatory stress and serve as mechanical retention of the definitive restorations. ${ }^{2}$ These retainers are cemented in the root canal by resin cements which require (or do not require) previous acid etching. ${ }^{3}$

Self-adhesive resin cements are commercially available and more easily applied than are conventional resin cements, in addition to combining characteristics of self-etching adhesive systems and composite resins. ${ }^{4}$ These cements contain functional acidic monomers capable of creating a double bonding mechanism between the dentin and the smear layer by the simultaneous demineralization and infiltration of the monomers, 
ensuring the bonding to the dental surface, as occurs with self-etching adhesives. ${ }^{4,5}$

Since self-adhesive resin cements are in close contact with the dentin, that is, without the presence of an adhesive layer, surface treatment of the tooth substrate becomes an important step in cementing the fiber post to the root canal. ${ }^{3}$ The current literature suggests not only the care with the dentin surface treatment to avoid adhesive fractures, but also treatments that can improve bond strength. ${ }^{6}$

In crown dentin, ethylenediaminetetraacetic acid (EDTA) used as pre-etching agent has an inhibitory effect on dentin matrix metalloproteinases (MMPs), ${ }^{7,8}$ producing more stable adhesive interfaces in the healthy dentin ${ }^{9}$ and sclerotic dentin over time..$^{10}$ Due to the chelating ability of EDTA, the increase in dentin permeability may favor the self-etching adhesion strategy. ${ }^{11}$

However, there are few studies in the literature evaluating the benefits of EDTA, and the ones available present conflicting results regarding the use of EDTA prior to the application of self-adhesive cements in the radicular dentin. ${ }^{12,13,14}$ While there are authors who have concluded that EDTA application does not affect the adhesive properties of self-adhesive cements, ${ }^{12}$ other authors have reported improved bonding. ${ }^{14}$

Because EDTA is a chelating and endodontic irrigating solution, attention is needed to its interaction with different adhesive systems and radicular dentin. ${ }^{15}$ The irrigation of the dentin substrate can directly interfere in the bond strength of fiber posts to the root canal ${ }^{16}$ and the choice of a correct protocol is crucial to maximize the bond strength between resin/dentin and resin/post.

Therefore, the objective of this study was to evaluate the influence of different EDTA concentrations on radicular dentin etching before bonding glass fiber posts with self-adhesive resin cements. The null hypothesis tested was that different concentrations of EDTA would not affect the bond strength of different self-adhesive resin cements.

\section{Methodology}

For this study, 78 extracted human single-rooted premolar teeth were selected after approval by the Research Ethics Committee of the School of Dentistry,
State University of Ponta Grossa (process number 1.795.649). The selected teeth should not present caries, root cracks, previous endodontic treatment, or incomplete root apex. The teeth should have a 14-mm root length measured from the cementoenamel junction (CEJ).

\section{Post space preparation}

Dental crowns were removed at the CEJ using a low-speed diamond saw (Isomet 1000, Buehler; Lake Bluff, USA), and root spaces were endodontically shaped with nickel-titanium rotary files SX to F3 (Dentsply Maillefer; Ballaigues, Switzerland) using a low-speed handpiece (X-smart; Dentsply Maillefer; Ballaigues, Switzerland). Between files, the root canals were irrigated with $2 \%$ chlorhexidine solution (Biodinamica; Rio de Janeiro, RJ, Brazil). Only the apical $4 \mathrm{~mm}$ was filled with gutta-percha points (Tanari; Manacapuru, Brazil) and calcium hydroxide-based root canal sealer (Sealer 26, Dentsply Maillefer; Ballaigues, Switzerland).

Roots were stored in eppendorf tubes with a gauze pad soaked in distilled water at $37^{\circ} \mathrm{C} \pm 1^{\circ} \mathrm{C}$ for one week. Thereafter, the root canals were prepared with the corresponding bur for shaping the Whitepost DC \#2 fiber post (FGM; Joinville, Brazil); irrigated abundantly with distilled water and subsequently dried for $5 \mathrm{~s}$ with an air jet and two paper points \#40 (Dentsply Maillefer; Ballaigues, Switzerland). The working length of the post space was $10 \mathrm{~mm}$ for all teeth.

\section{Experimental groups and sample preparation}

The roots were then divided into six groups $(n=13)$ by block randomization on a freely available website (www.sealedenvelope.com) according to the combination of the main factors: 1) Surface dentin treatment (distilled water [control], 17\% EDTA [Biodinamica; Rio de Janeiro, Brazil] and 24\% EDTA [Biodinamica]), and 2) self-adhesive resin cement (RelyXTM U200 RX, 3M ESPE, St. Paul, USA) and Multilink ${ }^{\circledR}$ Speed (ML, Ivoclar Vivadent; Barueri, Brazil). Ten teeth were used for bond strength evaluation and three were used for the microhardness analysis.

Root canals were irrigated with $2 \mathrm{~mL}$ of each irrigation solution agitated with a rigid microbrush (KG Sorensen, Cotia, Brazil) inside the root canal for $30 \mathrm{~s}$ and then washed with $2 \mathrm{~mL}$ of distilled water. 
The root canals were dried with compressed air for $5 \mathrm{~s}$ at $2 \mathrm{~cm}$ and dried with two \#40 paper points.

Glass fiber posts were horizontally sectioned in the coronal region with a water-cooled diamond cutting instrument to reduce post length to $13 \mathrm{~mm}$ (10 mm was cemented inside the root canal and $3 \mathrm{~mm}$ served as a guide for the light-curing protocol). After that, the posts were cleaned in $70 \%$ alcohol for $5 \mathrm{~s}$.

The two self-adhesive cements were handled and inserted into the root canal using a Centryx syringe (Maquira, Maringá, Brazil), following the manufacturer's recommendations. Glass fiber posts were then placed with finger pressure (equivalent to $35 \pm 5 \mathrm{~g}$, when performed on a surface of an analytical balance); excess of resin cement was removed and light-cured under continuous mode for $40 \mathrm{~s}$ using a light-curing unit with a light intensity of $1200 \mathrm{~mW} / \mathrm{cm}^{2}$ (Radii Plus, SDI; Victoria, Australia). The posts were light-cured on the cervical surface at a standardized distance of $3 \mathrm{~mm}$. All roots were stored in Eppendorf tubes with a gauze pad soaked in distilled water, at $37^{\circ} \mathrm{C} \pm 1{ }^{\circ} \mathrm{C}$ for one week.

Six 1-mm-thick slices were obtained by horizontally cutting the roots with a low-speed diamond saw (Isomet 1000, Buehler; Lake Bluff, USA) to create two cervical, two middle, and two apical slices from each root.

\section{Push-out bond strength test}

All slices (10 roots per group) were photographed on both sides with an optical microscope at 40X magnification (Olympus BX 51 model, Olympus; Tokyo, Japan), and their individual bonding areas were calculated using the Image J software (University of Wisconsin; Wisconsin, USA). The area was calculated as the lateral surface of a truncated cone using the following formula: ${ }^{17}$

$A=\pi(R+r)\left[h^{2}+(R-r)^{2}\right]^{0.5}$, where $\pi=3.14$, $R=$ coronal post radius, $r=$ apical post radius, and $h=$ root slice thickness.

Each slice was positioned with the cervical side down and subjected to constant compressive force ( $50 \mathrm{~kg}$ load cell at a crosshead speed of $0.5 \mathrm{~mm} / \mathrm{min}$ ) on a universal testing machine (Instron; Canton, USA). For this purpose, cylindrical tips with diameters compatible with the post at each third were used until debonding. The load for post dislodgement was recorded in Newtons $(\mathrm{N})$ and converted to MPa based on the bonding area $\left(\mathrm{mm}^{2}\right)$. After debonding, the failure modes were classified under a stereomicroscope (40X) as: adhesive (between resin cement and root dentin), cohesive (post, cement, or dentin), or mixed.

\section{Microhardness test}

The first slice of each third (cervical, middle, and apical) of the remaining three roots per group was used to evaluate the microhardness of the resin cement close to the root dentin. These sections were embedded in an acrylic resin with the cervical side facing up and polished down under wet conditions using 600-, 1200-, 1500-, 2000-, 2500- and 3000-grit silicon carbide papers (3M ESPE; St Paul, USA) for $30 \mathrm{~s}$ each. After storage for $24 \mathrm{~h}$ at $37^{\circ} \mathrm{C}$, the samples were subjected to a microhardness test using a Vicker microhardness tester (Shimadzu HMV2, Newage Testing Instruments Inc., Southampton, USA) with a load of $100 \mathrm{~g}$ for $15 \mathrm{~s}$. Four indentations per slice were performed as close to the dentin as possible in a clockwise direction (at $3,6,9$, and $12 \mathrm{~h}$ ). The length of the diagonal of the indentation was measured and Vickers values were calculated using the formula: $\mathrm{VHN}=1.8544 \mathrm{~F} / \mathrm{d}^{2}$, where 1.8544 is a constant; $F$ represents the force used in the test in $\mathrm{kgf}(0.1 \mathrm{kgf})$, and $d$ represents the average of the diagonals of the indentation ( $\mathrm{mm}$ ).

\section{Statistical analysis}

The data on push-outbond strength and microhardness for each self-adhesive resin cement were subjected to two-way ANOVA (surface treatment $v s$. root region) and a post-hoc Tukey's test $(\alpha=0.05)$. All calculations were performed using Sigma Plot 11 statistical software (Systat Software, San Jose, USA). Data on the fracture pattern were only assessed qualitatively.

\section{Results}

\section{Push-out bond strength}

For RelyXU200, the two-way ANOVA demonstrated that the cross-product interaction (surface treatment vs. root region) was not significant $(\mathrm{p}=0.702)$, and neither was root region $(p=0.473)$ (data not shown). Surface treatment was statistically significant (Table 1; $p<0.001$ ). The lowest bond strength value was observed 
in the 24\% EDTA group, whereas the control and 17\% EDTA groups were similar to one another.

For Multilink Speed, the two-way ANOVA demonstrated that only the cross-product interaction (surface treatment $v s$. root region) was statistically significant (Table 2; $\mathrm{p}=0.001$ ).

\section{Failure pattern}

The mixed failure mode was predominant in the control groups for both resin cements. For the groups with EDTA application, the adhesive failures between resin cement and root dentin were the most frequent, and more prevalent in the $24 \%$ EDTA groups. The

Table 1. Mean values and standard deviation of bond strength (MPa) for self-adhesive resin cement RelyX ${ }^{T M}$ U200.

\begin{tabular}{lcc}
\hline \multirow{2}{*}{ Control } & \multicolumn{2}{c}{ Surface treatment } \\
\cline { 2 - 3 } & $17 \%$ EDTA & $24 \%$ EDTA \\
\hline $14.5 \pm 3.2 \mathrm{~A}$ & $13.7 \pm 3.8 \mathrm{~A}$ & $7.8 \pm 2.6 \mathrm{~B}$ \\
\hline
\end{tabular}

* Different letters indicate statistically significant differences $(p<0.05)$. only cohesive failure occurred within the post, but at a lower rate (Figure).

\section{Microhardness test}

For RelyX U200, the two-way ANOVA demonstrated that the cross-product interaction (surface treatment vs. root region) was statistically significant (Table 3; $p=0.001)$. The highest microhardness value was observed in the cervical region for the control group and the lowest value in the cervical region for the 24\% EDTA group.

For Multilink Speed, the two-way ANOVA demonstrated that the cross-product interaction (surface treatment $v s$. root region) was not significant (Table $4 ; \mathrm{p}=0.683$ ), and neither was root region $(p=0.234)$. Only surface treatment was statistically significant $(p<0.05)$. The highest microhardness value was observed in the control group and the lowest value was observed in the $24 \%$ EDTA group, whereas the $17 \%$ EDTA group showed intermediate values.

Table 2. Mean values and standard deviation of bond strength $(\mathrm{MPa})$ for self-adhesive resin cement Multilink ${ }^{\circledR}$ Speed.

\begin{tabular}{lccc}
\hline \multirow{2}{*}{$\begin{array}{l}\text { Root } \\
\text { region }\end{array}$} & \multicolumn{3}{c}{ Surface treatment } \\
\cline { 2 - 4 } Control & $17 \%$ EDTA & $24 \%$ EDTA \\
\hline Cervical & $8.7 \pm 1.8 \mathrm{c}$ & $8.4 \pm 2.6 \mathrm{c}$ & $5.8 \pm 1.7 \mathrm{~d}$ \\
Middle & $13.3 \pm 1.7 \mathrm{~b}$ & $7.1 \pm 2.1 \mathrm{c}$ & $7.5 \pm 2.1 \mathrm{c}$ \\
Apical & $16.8 \pm 3.1 \mathrm{a}$ & $10.6 \pm 2.6 \mathrm{~b}$ & $7.7 \pm 3.5 \mathrm{c}$ \\
\hline
\end{tabular}

Table 3. Mean values and standard deviation of microhardness (Vickers) for self-adhesive resin cement RelyX ${ }^{\mathrm{TM}}$ U200.

\begin{tabular}{lccc}
\hline \multirow{2}{*}{$\begin{array}{l}\text { Root } \\
\text { region }\end{array}$} & Control & $17 \%$ EDTA & $24 \%$ EDTA \\
\cline { 2 - 4 } Cervical & $94.4 \pm 6.4 \mathrm{a}$ & $70.6 \pm 10.8 \mathrm{~b}$ & $55.3 \pm 5.8 \mathrm{~d}$ \\
Middle & $73.8 \pm 5.7 \mathrm{~b}$ & $76.6 \pm 9.6 \mathrm{~b}$ & $58.8 \pm 4.1 \mathrm{~d}$ \\
Apical & $70.4 \pm 4.7 \mathrm{~b}$ & $70.0 \pm 9.2 \mathrm{c}$ & $58.5 \pm 2.0 \mathrm{~d}$ \\
\hline * Different letters indicate statistically significant differences $(\mathrm{p}<0.05)$.
\end{tabular}

* Different letters indicate statistically significant differences $(p<0.05)$.

Faillure pattern

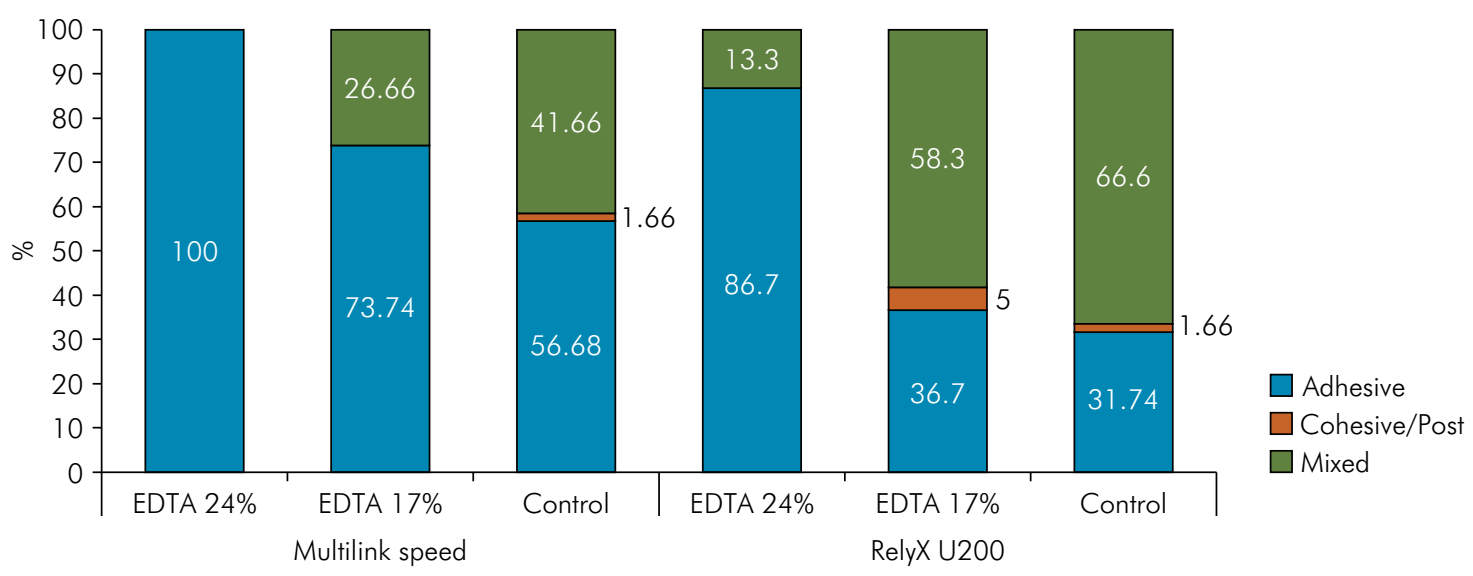

Figure. Representative graph of the fracture patterns observed after bond strength testing for the different experimental groups. 
Table 4. Mean values and standard deviation of microhardness (Vickers) for self-adhesive resin cement Multilink ${ }^{\circledR}$ Speed.

\begin{tabular}{lcc}
\hline Control & $17 \%$ EDTA & $24 \%$ EDTA \\
\hline $57.4 \pm 7.1 \mathrm{~A}$ & $54.4 \pm 5.4 \mathrm{AB}$ & $51.8 \pm 3.3 \mathrm{~B}$ \\
\hline * Different letters indicate statistically significant differences $(\mathrm{p}<0.05)$
\end{tabular}

\section{Discussion}

The results of this study indicate that the tested EDTA concentrations interfere in the push-out bond strength and microhardness; thus, the null hypothesis was rejected. This whole study was performed by calibrated and experienced professionals; however, the results obtained for the push-out test do not match most of those described in the literature. The use of 24\% EDTA compared to other lower concentrations of this chelating agent promotes a cleaner surface and significantly increases the contact area of the dentin substrate. ${ }^{18}$ However, the expectation of greater results was not fulfilled, since the use of these solutions did not positively interfere with the tests in this study.

For the RX group, 24\% EDTA irrigation showed the lowest BS results. The literature has shown that $24 \%$ EDTA applied to root dentin was significantly more effective than all lower concentrations of EDTA with regard to smear removal capacity. ${ }^{19}$ The excessive removal of the smear layer by calcium-ion chelation theoretically is likely to reduce the chemical bonding of the self-adhesive cement to hydroxyapatite. ${ }^{20,21}$

A relatively recent study has evaluated the bond strength of one of the resin cements assessed in the present study (RelyX U200) with the application of 17\% EDTA and satisfactory results for BS. ${ }^{15}$ However, in that study, the EDTA solution was applied and subsequently activated by an ultrasonic tip, which may explain the conflicting results with the present research. Sonic vibration transmits energy to the fluids, allowing them to reach deeper areas than would manual application. ${ }^{22,23}$

BS values were conflicting for ML cement. In most studies on the bond strength of fiber posts, the cervical portion has the highest BS values, almost unanimously. ${ }^{24,25,26}$ However; in this study, the middle and apical thirds presented higher values with distilled water. Because self-adhesive resin cements show an affinity for the composition of composite resins, in addition to containing an unfavorable factor (e.g., C-factor). ${ }^{27}$ The cervical dentinal tubules are larger than in the middle and apical portions, and root canal diameter is larger as well. ${ }^{28}$ This may possibly explain the conflicting results with the literature.

Unlike BS values, $\mathrm{MH}$ results are in line with those described in the literature. For both self-adhesive resin cement systems, irrigation with 24\% EDTA showed lower values. The MH test was carried out as close to the substrate as possible, and any type of negative adhesion can compromise complete polymerization and, consequently, the hardness of the cement. EDTA can partially remove hydroxyapatite and non-collagen proteins selectively, avoiding major changes in the dentin structure. ${ }^{29}$ Probably, the higher concentration of $24 \%$ EDTA excessively removed this matrix, causing collagen fibrils to collapse and compromising the interaction of RelyX U200 and Multilink Speed cements with the radicular dentin.

Theoretically, the higher concentration of EDTA should facilitate the infiltration of resin cements into the dentinal tubules, since the chelating action of EDTA significantly promotes their cleaning. ${ }^{18}$ However, the solution excessively removes the smear layer, which is directly linked to the adhesion mechanism of the self-adhesive systems. ${ }^{30}$ Our study suggests that self-adhesive resin cements not only depend on the chemical bonding to dentinal hydroxyapatite, but also on the modification and incorporation of the smear layer for complete adhesion.

Unlike most studies that evaluated the failure pattern after the push-out test, this study demonstrated the predominance of mixed and non-adhesive fracture patterns. ${ }^{31,32}$ Another recent study on self-adhesive cements corroborated the fracture pattern found in the present study. ${ }^{33}$ Mixed fractures are interesting and promising in terms of bond strength, since they represent better interaction of the cement with the dentin, preventing the cement from being removed from the substrate as easily as in adhesive fractures. ${ }^{34}$

The 24\% EDTA solution is sold in more practical packaging (gel tube) than is conventional 17\% EDTA (liquid), which may make it more attractive to dentists. 
Therefore, companies should be cautious about contraindications to the use of this solution prior to self-adhesive cementation. Further studies are needed to evaluate adhesion over the long term.

\section{Conclusion}

Despite the limitations of this study, EDTA is not recommended as pretreatment for fiber post cementation using self-adhesive cements. The use of $24 \%$ EDTA affected the bond strength to the root dentin, microhardness of the cement, and the failure pattern. The use of $17 \%$ EDTA influenced microhardness.

The use of 24\% EDTA negatively affects the bond strength of fiber posts to the root canal with the use of self-adhesive cements.

\section{Acknowledgements}

This study was partially financed by the Coordenação de Aperfeiçoamento de Pessoal de Nível Superior - Brasil (CAPES) - Finance Code 001. The authors also thank the Fundação Araucária (Brazil) for partial financial support.

\section{References}

1. Tang W, Wu Y, Smales RJ. Identifying and reducing risks for potential fractures in endodontically treated teeth. J Endod. 2010 Apr;36(4):609-17. https://doi.org/10.1016/i.joen.2009.12.002

2. Elsharkawy DA, Attia MS. Finite element analysis of stress distribution in weakened teeth restored with different post core materials. Egypt Dent J. 2018;64(4):3957-63. https://doi.org/10.21608/edj.2018.79511

3. Reis A, Loguercio AD, Bitter K, Perdigão J. Adhesion to root dentin: a challenging task. restoration of root canal-treated teeth. Springer; 2016.

4. Manso AP, Carvalho RM. Dental cements for luting and bonding restorations: self-adhesive resin cements. Dent Clin North Am. 2017 Oct;61 (4):821-34. https://doi.org/10.1016/i.cden.2017.06.006

5. Ferracane JL, Stansbury JW, Burke FJ. Self-adhesive resin cements - chemistry, properties and clinical considerations. J Oral Rehabil. 2011 Apr;38(4):295-314. https://doi.org/10.1111/j.1365-2842.2010.02148.x

6. Machry RV, Fontana PE, Bohrer TC, Valandro LF, Kaizer OB. Effect of different surface treatments of resin relined fiber posts cemented with self-adhesive resin cement on push-out and microtensile bond strength tests. Oper Dent. 2020 Jul;45(4):E185-95 https://doi.org/10.2341/19-108-L

7. Thompson JM, Agee K, Sidow SJ, McNally K, Lindsey K, Borke J, et al. Inhibition of endogenous dentin matrix metalloproteinases by ethylenediaminetetraacetic acid. J Endod. 2012 Jan;38(1):62-5. https://doi.org/10.1016/i.joen.2011.09.005

8. Toledano M, Yamauti M, Osorio E, Osorio R. Zinc-inhibited MMP-mediated collagen degradation after different dentine demineralization procedures. Caries Res. 2012;46(3):201-7. https://doi.org/10.1159/000337315

9. Imbery TA, Kennedy M, Janus C, Moon PC. Evaluating EDTA as a substitute for phosphoric acid-etching of enamel and dentin. Gen Dent. 2012 Mar-Apr;60(2):e55-61.

10. Martini EC, Parreiras SO, Gutierrez MF, Loguercio AD, Reis A. Effect of different protocols in preconditioning with EDTA in sclerotic dentin and enamel before universal adhesives applied in self-etch mode. Oper Dent. 2017 May/Jun;42(3):284-96. https://doi.org/10.2341/16-014-L

11. Bighetti Trevisan RL, Scatolin RS, Castro Raucci LM, Raucci Neto W, Froner IC. Effects of EDTA gel and chlorhexidine gel on root dentin permeability. Microsc Res Tech. 2018 Feb;81(2):191-7. https://doi.org/10.1002/jemt.22963

12. Muana HL, Hiraishi N, Nakajima M, Kong K, Tagami J. Effect of the dentin chelating agents phytic acid and edta on degree of conversion, microhardness, and bond strength of chemical-curing self-adhesive cements. J Adhes Dent. 2019;21(4):299-306. https://doi.org/10.3290/i.jad.a42997

13. Souza MA, Bonacina LV, Ricci R, Padilha Rauber MG, Zuchi N, Hoffmann IP, et al. Influence of final irrigation protocols and type of resin cement on bond strength of glass fiber posts in root dentin previously treated with photodynamic therapy. Photodiagn Photodyn Ther. 2019 Jun;26:224-8. https://doi.org/10.1016/i.pdpdt.2019.04.007

14. Alkhudhairy Fl, Yaman P, Dennison J, McDonald N, Herrero A, Bin-Shuwaish MS. The effects of different irrigation solutions on the bond strength of cemented fiber posts. Clin Cosmet Investig Dent. 2018 Oct;10:221-30. https://doi.org/10.2147/CCIDE.S155688

15. Barreto MS, Rosa RA, Seballos VG, Machado E, Valandro LF, Kaizer OB, et al. Effect of intracanal irrigants on bond strength of fiber posts cemented with a self-adhesive resin cement. Oper Dent. 2016 Nov/Dec;41(6):e159-67. https://doi.org/10.2341/15-246-L 
16. Jitumori RT, Bittencourt BF, Reis A, Gomes JC, Gomes GM. Effect of root canal irrigants on fiber post bonding using self-adhesive composite cements. J Adhes Dent. 2019;21(6):537-44. https://doi.org/10.3290/i.jad.a43609

17. Coniglio I, Magni E, Cantoro A, Goracci C, Ferrari M. Push-out bond strength of circular and oval-shaped fiber posts. Clin Oral Investig. 2011 Oct;15(5):667-72. https://doi.org/10.1007/s00784-010-0448-0

18. Daghustani M, Alhammadi A, Merdad K, Ohlin J, Erhardt F, Ahlquist M. Comparison between high concentration EDTA (24\%) and low concentration EDTA (3\%) with surfactant upon removal of smear layer after rotary instrumentation: a SEM study. Swed Dent J. $2011 ; 35(1): 9-15$.

19. Blomlöf J, Blomlöf L, Lindskog S. Effect of different concentrations of EDTA on smear removal and collagen exposure in periodontitis-affected root surfaces. J Clin Periodontol. 1997 Aug;24(8):534-7. https://doi.org/10.1111/j.1600-051X.1997.tb00225.x

20. Baena E, Flores A, Ceballos L. Influence of root dentin treatment on the push-out bond strength of fiber posts. Odontology. 2017 Apr;105(2):170-7. https://doi.org/10.1007/s10266-016-0252-7

21. Simões TC, Luque-Martinez Í, Moraes RR, Sá A, Loguercio AD, Moura SK. Longevity of bonding of self-adhesive resin cement to dentin. Oper Dent. 2016 May-Jun;41(3):E64-72. https://doi.org/10.2341/14-266-LR

22. Cuadros-Sanchez J, Szesz A, Hass V, Patzlaff RT, Reis A, Loguercio AD. Effects of sonic application of adhesive systems on bonding fiber posts to root canals. J Endod. 2014 Aug;40(8):1201-5. https://doi.org/10.1016/i.joen.2013.12.034

23. Mena-Serrano A, Costa TR, Patzlaff RT, Loguercio AD, Reis A. Effect of sonic application mode on the resin-dentin bond strength and dentin permeability of self-etching systems. J Adhes Dent. 2014 Oct;16(5):435-40. https://doi.org/10.3290/i.jad.a32810

24. Suzuki TYU, Gomes-Filho JE, Fraga Briso ALF, Assunção WG, Santos PH. Influence of the depth of intraradicular dentin on the pushout bond strength of resin materials. J Investig Clin Dent. 2019 Nov;10(4):e12461. https://doi.org/10.1111/jicd.12461

25. Pereira KF, Vencão AC, Magro MG, Belizário LG, Porto TS, Andrade MF, et al. Effect of endodontic retreatment on the bond strength of resin cements to root canal dentin. Am J Dent. 2019 Jun;32(3):147-51.

26. Memon S, Mehta S, Malik S, Nirmal N, Sharma D, Arora H. Three-dimensional finite element analysis of the stress distribution in the endodontically treated maxillary central incisor by glass fiber post and dentin post. J Indian Prosthodont Soc. 2016 Jan-Mar;16(1):70-4. https://doi.org/10.4103/0972-4052.167933

27. Boing TF, Gomes GM, Gomes JC, Reis A, Gomes OM. Is the bonding of self-adhesive cement sensitive to root region and curing mode? J Appl Oral Sci. 2017 Jan-Feb;25(1):2-9. https://doi.org/10.1590/1678-77572015-0430

28. Mannocci F, Pilecki P, Bertelli E, Watson TF. Density of dentinal tubules affects the tensile strength of root dentin. Dent Mater. 2004 Mar;20(3):293-6. https://doi.org/10.1016/S0109-5641(03)00106-4

29. Ballal NV, Jain I, Tay FR. Evaluation of the smear layer removal and decalcification effect of QMix, maleic acid and EDTA on root canal dentine. J Dent. 2016 Aug;51:62-68. https://doi.org/10.1016/i.jdent.2016.06.001

30. Kambara K, Nakajima M, Hosaka K, Takahashi M, Thanatvarakorn O, Ichinose S, et al. Effect of smear layer treatment on dentin bond of self-adhesive cements. Dent Mater J. 2012;31(6):980-7. https://doi.org/10.4012/dmi.2012-031

31. Bakaus TE, Gruber YL, Reis A, Gomes JC, Gomes GM. Bonding properties of universal adhesives to root canals prepared with different rotary instruments. J Prosthet Dent. 2019 Feb;121(2):298-305. https://doi.org/10.1016/i.prosdent.2018.02.013

32. Gruber YL, Bakaus TE, Gomes OM, Reis A, Gomes GM. Effect of dentin moisture and application mode of universal adhesives on the adhesion of glass fiber posts to root canal. J Adhes Dent. 2017;19(5):385-93. https://doi.org/10.3290/i.jad.a.38998

33. Kul E, Yeter KY, Aladag LI, Ayrancı LB. Effect of different post space irrigation procedures on the bond strength of a fiber post attached with a self-adhesive resin cement. J Prosthet Dent. 2016 May;115(5):601-5. https://doi.org/10.1016/i.prosdent.2015.10.010

34. Victorino KR, Kuga MC, Duarte MA, Cavenago BC, Só MV, Pereira JR. The effects of chlorhexidine and ethanol on push-out bond strength of fiber posts. J Conserv Dent. 2016 Jan-Feb;19(1):96-100. https://doi.org/10.4103/0972-0707.173210 